$$
1771-28119
$$

NASA TECHNICAL ME MORANDUM

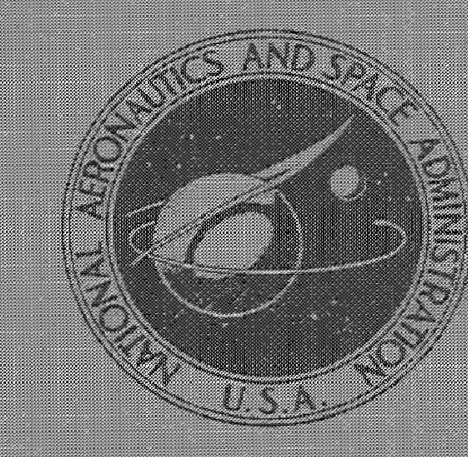

NASA TM X-2206

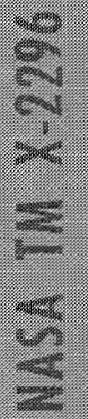

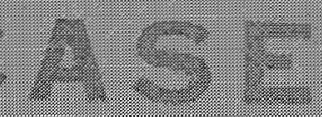

$\mathrm{CO}$

\title{
A METHOD FOR PRODUCING MONOENERGETIC NEUTRONS AT KILOVOLT ENERGIES
}

by Stephen E. Binney, Harvey Amster, Rudolpb J. Heminger, and Hans Mark

Lervis Research Center

Cleveland, Ohio 44135

MATIONAL AERONAUTICS ANG SPACE ADMINISTRATION - WASHINGTON, D. F. JUNE 


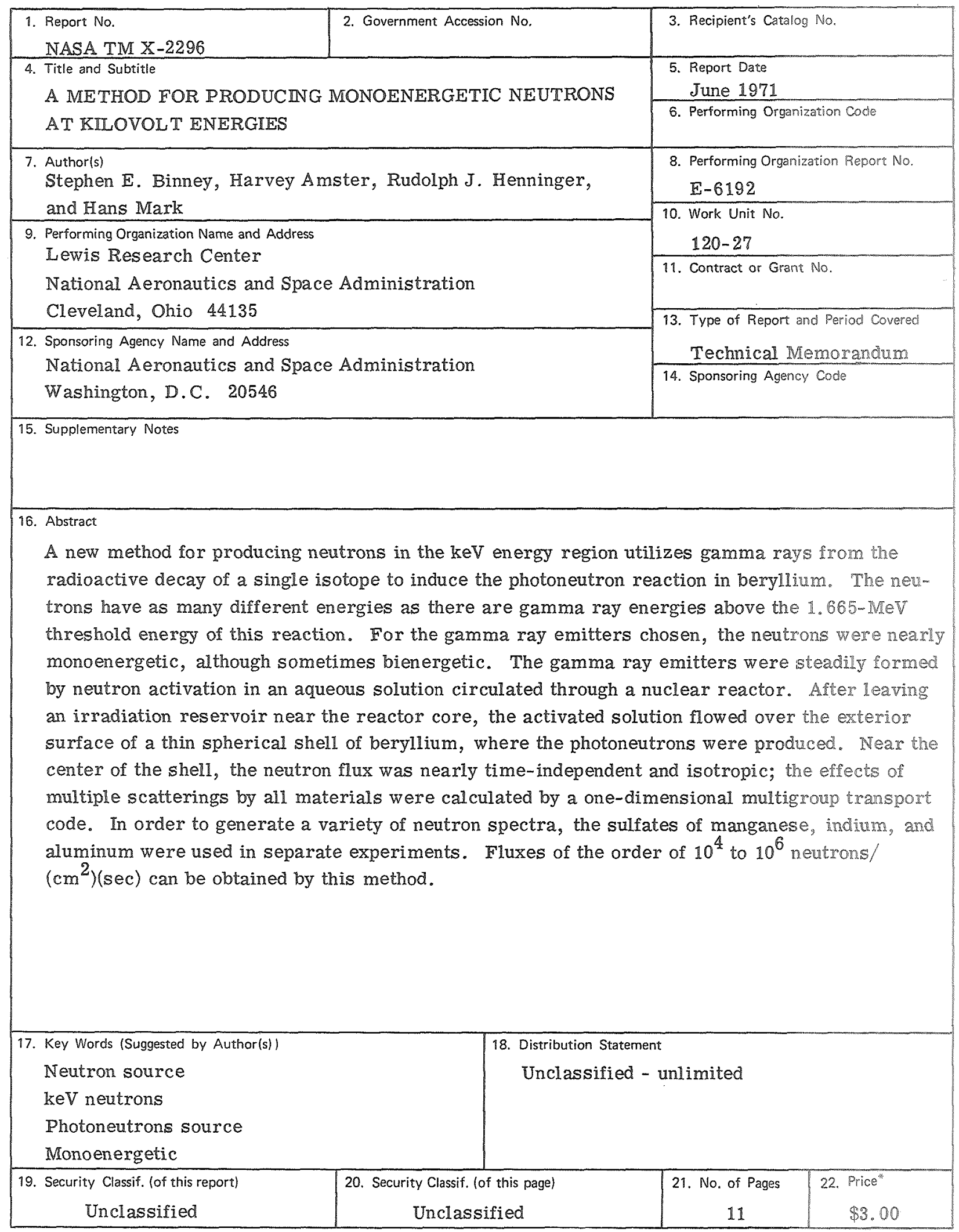

*For sale by the National Technical Information Service, Springfield, Virginia 22151 


\title{
A METHOD FOR PRODUCING MONOENERGETIC NEUTRONS AT KILOVOLT ENERGIES
}

\author{
by Stephen E. Binney, Harvey Amster, * Rudolph J. Henninger, ${ }^{\dagger}$ \\ and Hans Mark $\ddagger$ \\ Lewis Research Center
}

\section{SUMMARY}

A new method for producing neutrons in the keV energy region utilizes gamma rays from the radioactive decay of a single isotope to induce the photoneutron reaction in beryllium. The neutrons have as many different energies as there are gamma ray energies above the $1.665-\mathrm{MeV}$ threshold energy of this reaction. For the gamma ray emitters chosen, the neutrons were nearly monoenergetic, although sometimes bienergetic. The gamma ray emitters were steadily formed by neutron activation in an aqueous solution circulated through a nuclear reactor. After leaving an irradiation reservoir near the reactor core, the activated solution flowed over the exterior surface of a thin spherical shell of beryllium, where the photoneutrons were produced. Near the center of the shell, the neutron flux was nearly time-independent and isotropic; the effects of multiple scatterings by all materials were calculated by a one-dimensional multigroup transport code. In order to generate a variety of neutron spectra, the sulfates of manganese, indium, and aluminum were used in separate experiments.

The spectra of the neutron sources resulting from the photoneutron reaction in beryllium peak in the $\mathrm{keV}$ energy region. This type of neutron source is considerably more monoenergetic than the spectra in a nuclear reactor or from solid $(\alpha, n)$ neutron sources.

Controlling the flow of the aqueous solution of gamma ray emitters provides a reasonably quick and simple method of turning the neutron source "on" and "off" Also the use of several different gamma ray emitters, one at a time, provides a variety of neutron spectra, each of which peaks at a different energy.

The neutron flux obtained from this type of source (of the order of $10^{4}$ to $10^{6}$ neutrons $/\left(\mathrm{cm}^{2}\right)(\mathrm{sec})$ ) may be too low for some applications. However, this flux is comparable to or greater than the flux at a distance of 10 centimeters from a $10^{7}$ neutron per second solid source.

* Professor of Nuclear Engineering, University of California, Berkeley, California.

†Graduate Student, University of California, Berkeley, California,

*Director of Ames Research Center, Moffett Field, California, formerly Chairman, Department of Nuclear Engineering, University of California, Berkeley, Califormia. 


\section{INTRODUCTION}

Sources of monoenergetic neutrons at a variety of energies would facilitate the acquisition of nuclear data and the calibration of spectral measuring instruments. These sources are especially needed in the intermediate (keV) energy region, where neutron cross sections are poorly resolved and neutron spectrometers for fast reactors are being developed.

There are several methods for producing neutrons in the keV region, each with characteristic advantages and disadvantages. For example, a nuclear reactor is a very strong neutron source, but its energy spectrum is broad and often poorly known; a linear accelerator can produce a moderate yield of neutrons at various energies, but operation is not practical over long periods of time.

Monoenergetic neutrons in the $\mathrm{keV}$ energy region can be produced by a $(\gamma, \mathrm{n})$ reaction when monoenergetic gamma rays are used to irradiate certain materials, but these sources generally have a fairly low yield. In the method described in this report, however, the gamma ray emitters are activated in a recirculating aqueous solution as it passes near the core of a nuclear reactor, and, as a result, the gamma ray intensity from even relatively short-lived isotopes can steadily be maintained at a high level. photoneutrons from a beryllium $\left({ }^{9} \mathrm{Be}\right)$ spherical shell are emitted when the radioactive solution flows around its outer surface.

This source was developed specifically in order to calibrate a new type of instrument developed by the authors (unpublished data), but it is expected to be useful for other applications as well.

\section{PHOTONEUTRON REACTION}

Conservation of mass, energy, and momentum imply that the energy $E_{n}(\theta)$ of a photoneutron produced by a gamma ray of energy $\mathbb{E}_{\gamma}$ is given by

$$
\begin{aligned}
\mathbb{E}_{n}(\theta)=\frac{M\left(\mathbb{E}_{\gamma}^{2}-Q\right)-\frac{\mathbb{E}_{\gamma}^{2}}{2}}{m+\mathbb{M}}+\frac{m E_{\gamma}^{2} \cos ^{2} \theta}{(m+M)^{2}} \\
+\frac{E_{\gamma} \cos \theta \sqrt{(2 m M)(m+M)\left(E_{\gamma}-Q\right)-\left(E_{\gamma}^{2}\right)\left(m M+m^{2} \sin ^{2} \theta\right)}}{(m+M)^{2}}
\end{aligned}
$$


where $\mathbb{M}$ is the mass of the recoil isotope, $Q$ is the difference between the initial and final rest masses of all the particles, $m$ is the neutron mass, and $\theta$ is the emission angle of the photoneutron with respect to the direction of the incident gamma ray. The masses $M, m$, and $Q$ are expressed in this report in energy units. For typical gamma ray energies and a beryllium target, both $M$ and $m \gg E_{\gamma}$, so that equation (1) can be simplified to

$$
E_{n}(\theta) \approx \frac{M\left(E_{\gamma}-Q\right)}{m+M}+\frac{E_{\gamma} \cos \theta \sqrt{(2 m M)(m+M)\left(E_{\gamma}-Q\right)}}{(m+M)^{2}}
$$

Beryllium is chosen as the gamma ray target principally because the photoneutron threshold energy of ${ }^{9} \mathrm{Be}$ is $1.665 \mathrm{MeV}$, the lowest known of all stable isotopes. For gamma ray energies not too far above the threshold energy, the photoneutron reaction is isotropic (ref. 1). Thus, the average neutron energy $\overline{E_{n}}$, integrated over all angles of emission with respect to the incident gamma ray, is just the first term of equation (2).

The upper part of table I lists those photoneutron sources, aluminum (AI), manganese (Mn), and indium (In), which were used in the experimental apparatus and demonstrates the nearly monoenergetic nature of the photoneutrons. The first three columns specify the radioactive gamma ray emitters, their half-lives, and their principal gamma ray energies above the $1.665-\mathrm{MeV}$ threshold energy. The last two columns give the average energy of the emitted neutrons and the maximum percent deviation of neutron. energies from the average. This quantity is merely the ratio of the coefficient of $\cos \theta$ in the second term of equation (2) to the first term, expressed in percent. Some other isotopes can be used as gamma ray sources. Five of these, antimony (Sb), rubidium $(\mathbb{R b})$, molybdenum $(\mathrm{Mo})$, chlorine $(\mathrm{Cl})$, and sodium $(\mathrm{Na})$, and their predominant gamma rays are listed in the lower part of table $I$. These sources vary as to how well they satisfy other desirable criteria described in the next section.

It is seen that photoneutrons produced by this reaction have energies within less than 6 percent of an average value. This value neglects moderation of the photoneutrons, as well as Compton scattering of the gamma rays, in the beryllium or the solution of gamma ray emitters. Depending upon the source geometry, the former effect could alter the photoneutron spectrum greatly. Compton scattering, which also depends on the souce geometry, is usually a relatively small effect, since the thicknesses involved are usually much less than one mean free path. 1

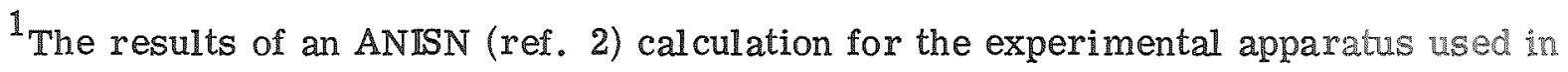
this study indicated that the gamma ray flux in the source energy group was about 250 times as large as the gamma ray flux in those lower energy groups above the threshold energy. 


\section{PHOTONEUTRON SOURCE}

It may be desirable for the neutron source strength not to vary significantly during the course of an experiment. One method of achieving this would be to use gamma ray emitters with half-lives so long that the gamma ray intensity, and hence the neutron source strength, would decrease very little. However, this method has the disadvantage of requiring a long irradiation time and/or a large mass of material to be activated. The long-lived isotopes also create a storage problem.

Therefore, an alternate method for keeping the gamma ray source strength constant was devised. An aqueous solution of one of the isotopes listed in the top portion of table I was pumped through a recirculating loop. Part of the loop was located near the core of a nuclear reactor, and neutron activation of the isotope produced a solution which emitted gamma rays. This solution was then pumped around a thin shell of beryllium, which then emitted photoneutrons.

Certain properties are desirable for the isotopes used in the solutions:

(1) Large neutron activation cross section

(2) High isotopic abundance

(3) Short half-life

(4) Capability of producing a gamma ray emitting daughter with a high fractional occurrence and an energy greater than the beryllium photoneutron threshold (1.665 MeV), but less than the second excited state in beryllium (2.429 MeV); onlly one such gamma ray should have an energy above the threshold energy so as to yield only one group of monoenergetic neutrons

(5) High solubility of one of its chemical compounds in water; this compound should contain no other isotopes which could be activated to emit a gamma ray with an energy greater than $1.665 \mathrm{MeV}$

(6) Low cost

The gamma ray sources used to test this method of producing neutrons were the sulfates of those isotopes indicated in table I. These isotopes have most of the properties just listed. In particular, aluminum produces neutrons at one energy; however, manganese and indium, each having two principal gamma rays with energies above 1.665 MeV, produce neutrons at two energies. Knowledge of the fractional occurrence of these gamma rays and of the photoneutron cross section at these energies enables the relative yield of each neutron group to be calculated.

\section{APPARATUS}

The photoneutron source was designed to incorporate or optimize certain advantageous properties. The apparatus was made spherically symmetric so that a one- 
dimensional transport code could be used to calculate the flux spectrum inside. The amount of radioactive solution adjacent to the beryllium was sufficient to strengthen the gamma ray intensity without moderating neutrons enough to alter the monenergetic character of the flux significantly. The spherical source was made large enough for the neutron flux to be nearly isotropic and of constant strength near its center.

Figure 1 shows the recirculating loop that was installed in a radial beam port of the Berkeley Research Reactor. The reactor is a TRIGA Mark III capable of $\mathbb{1}$ - MW steady state operation.

At the inner end of the beam port, a $4000-\mathrm{cm}^{3}$ cylinder served as a reservoir for the solution during activation. The thermal neutron flux at this location is $5 \times 10^{12}$ neutrons $/\left(\mathrm{cm}^{2}\right)(\mathrm{sec})$ at full power. The entire loop contained $28000 \mathrm{~cm}^{3}$ of solution, which was circulated by a pump. Cooling coils along a portion of the loop maintained a uniform temperature of the solution during circulation.

Because a saturated activity can quickly be attained for short-lived isotopes, the neutron source strength is constant as long as the reactor maintains a constant power level. This statement is valid only if the half-life of the solution is long compared to the recirculating cycle time. The recycle time for the apparatus discussed in this report was about 1 minute.

The loop was constructed of copper. Copper was chosen because (1) it is easy to solder and form, (2) it has short half-lives which would not cause any long-term storage and handling problems, and (3) it emits no gamma rays with energies above the photoneutron threshold energy. The last item is important, because copper is corrodible and some did get into solution and become activated: during 111 clock hours (representing $55 \mathrm{MW}-\mathrm{hr}$ ) of operation, about $300 \mathrm{~g}$ of copper, as determined by activation analysis, were corroded from the loop into the solutions.

The portion of the flow loop which housed the neutron source itself was contained between two spherical copper shells (see fig. 2). Many thin sheets $(1.6 \mathrm{~mm}$ ) of beryllium, having square and triangular areas of a few square centimeters, were epoxied to the inside of the inner copper shell. This effective spherical shell of beryllium was $46 \mathrm{~cm}$ in diameter, large enough for the flux to be nearly isotropic at all positions within. a few centimeters of the center of the sphere. The gap in the region between the copper walls, where the solution circulated through the loop, was about $2.5 \mathrm{~cm}$. This spacing was chosen as a compromise between a stronger neutron source and increased Compton scattering of the gamma rays, which would affect the gamma ray spectrum and hence the neutron spectrum. The sphere was designed with a removable top to allow the in-sertion of samples to be activated.

In addition, the flow loop ran through the center of a large manganous sulfate bath (not shown in fig. 1). A small cylinder of beryllium placed around the copper tubing (filled with the gamma ray emitting solution) served as a photoneutron source for the 
bath. The neutron intensity (as determined by measuring the bath activity) of this beryllium sleeve provided a relative measurement of the photoneutron intensity of the spherical shell source mentioned previously. This result was obtained for each gamma ray source used without the necessity of knowing the photoneutron cross sections involved.

Because of the large gamma ray source strength involved in these experiments, it was necessary to construct personnel shielding. A concrete cave with walls and roof $92 \mathrm{~cm}$ thick reduced the dose rate to $3 \mathrm{mR} / \mathrm{hr}$ at the outer surface of the wall when the gamma ray activity in the flow $100 \mathrm{p}$ was $500 \mathrm{Ci}$. Separate neutron and gamma ray shielding was provided in the reactor beam port so that gamma rays and neutrons from the reactor core would not interfere with the photoneutrons being produced outside the beam port. A beam catcher, consisting of boron-loaded polyethylene bricks, was placed in front of the beam tube to further prevent interference by core neutrons.

\section{RESULTS AND DISCUSSION}

The radioactivity of the gamma ray emitters was controlled so that it did not exceed an authorized limit. A total activity of $500 \mathrm{Ci}$ in the loop produced a dose rate of $4000 \mathrm{R} / \mathrm{hr}$ at the outer surface of the copper sphere. The activity could have been increased several hundred times by using a reactor with a higher neutron flux and also by using a higher concentration of the isotope in solution. With the exception of aluminum sulfate, mone of the solutions used was near chemical saturation (see table II).

The neutron flux at the center of the sphere was determined by activation of a 1.3cm-diameter sphere of packed iodine powder surrounded by a cadmium shield. Epicadmium neutron fluxes of 28,4 , and 55 neutrons $/\left(\mathrm{cm}^{2}\right)(\mathrm{sec})$ were obtained per curie of the manganese, indium, and aluminum sources, respectively. Depending on the source used, the actual fluxes were about $3 \times 10^{3}$ to $10^{4}$ neutrons $/\left(\mathrm{cm}^{2}\right)(\mathrm{sec})$ (see table II).

The neutron flux produced by this method is a factor of about $10^{8}$ to $10^{9}$ lower than the reactor flux that activated the solution. Thus, in the process of utilizing an $(n, \gamma)$ reaction and then a $(\gamma, n)$ reaction, a tremendous loss in intensity is experienced. What is gained, of course, is a more monoenergetic spectrum than the reactor spectrum, as well as a spectrum having most of the neutrons in the keV energy region.

The neutron spectrum at the center of the sphere is shown in figure 3 . This spectrum was calculated by the multigroup transport code ANISN (ref. 2). The beryllium shell was taken as a uniform isotropic source for this calculation. The peak at the source energy, which is $400 \mathrm{keV}$ in this calculation, is due to uncollided neutrons. The maxima in the spectrum at energies below the direct source are due mainly to backscattering from the hydrogen and oxygen in the aqueous solution and concrete shielding and from the copper in the spherical shells. The spectrum could be made even closer to monoenergetic by reducing the thickness of the aqueous solution around the beryllium 
and, to a lesser extent, by placing the concrete shielding farther from the beryllium.

\section{CONCLUDING REMARKS}

The spectra of the neutron sources resulting from the photoneutron reaction in beryllium peak in the $\mathrm{keV}$ energy region. This type of neutron source is considerably more monoenergetic than the spectra in a nuclear reactor or from solid $(\alpha, n)$ neutron sources.

Controlling the flow of the aqueous solution of gamma ray emitters provides a reasonably quick and simple method of turning the neutron source "on" and "off." Also, the use of several different gamma ray emitters, one at a time, provides a variety of neutron spectra, each of which peaks at a different energy.

Because of the large gamma ray activity present, personnel shielding is required. For the same reason, this type of neutron source would not be desirable for neutron detectors which are also sensitive to gamma rays.

Any radioactive material presents certain handling and storage problems. However, additional care is required when handling radioactive liquids, such as those discussed in this report, although the short half-lives tend to minimize this problem.

The neutron flux obtained from this type of source (of the order of $10^{4}$ to $10^{6}$ neutrons $\left./\left(\mathrm{cm}^{2}\right)(\mathrm{sec})\right)$ may be too low for some applications. However, this flux is comparable to or greater than the flux at a distance of $10 \mathrm{~cm}$ from a $10^{7}$ neutron/sec solid source. This method of producing neutrons is therefore useful for a range of applications where a nearly monoenergetic $\mathrm{keV}$ neutron source is needed.

Lewis Research Center,

National Aeronautics and Space Administration, Cleveland, Ohio, March 9, 1971, 120-27.

\section{REFERENCES}

1. Jakobson, Mark J.: Photodisintegration of $\mathrm{Be}^{9}$ from Threshold to $5 \mathrm{MeV}$. Phys. Rev., vol. 123, no. 1, July 1, 1961, pp. 229-230.

2. Engle, Ward W., Jr.: A User's Manual for ANISN: A One Dimensional Discrete Ordinates Transport Code with Anisotropic Scattering. Rep. K-1693, Union Carbide Corp., Mar. 30, 1967. 
TABLE I. - PHOTONEUTRON SOURCES

\begin{tabular}{|c|c|c|c|c|}
\hline Source & $\begin{array}{c}\text { Half-life, } \\
t_{1 / 2}\end{array}$ & $\begin{array}{c}\text { Principal } \\
\text { gamma } \\
\text { ray } \\
\text { energy, } \\
\mathrm{E}_{\gamma^{\prime}} \\
\mathrm{keV}\end{array}$ & $\begin{array}{c}\text { Average neutron } \\
\text { energy, } \\
\overline{\mathrm{E}}_{\mathrm{n}}, \\
\mathrm{keV}\end{array}$ & $\begin{array}{l}\text { Maximum deviation } \\
\text { of neutron energy } \\
\text { from average, } \\
\frac{E_{\mathrm{n}}(0)-\overline{E_{n}}}{\overline{E_{n}}} \times 100, \\
\text { percent }\end{array}$ \\
\hline \multicolumn{5}{|c|}{ Used in this study } \\
\hline $\begin{array}{l}{ }^{28} \mathrm{Al}-\mathrm{Be} \\
{ }^{56} \mathrm{Mn}-\mathrm{Be} \\
{ }^{116}{ }_{\mathrm{In}-\mathrm{Be}}\end{array}$ & $\begin{array}{l}2.31 \mathrm{~min} \\
2.576 \mathrm{hr} \\
54.0 \mathrm{~min}\end{array}$ & $\begin{array}{l}1780 \\
1811 \\
2110 \\
1753 \\
2111\end{array}$ & $\begin{array}{r}102 \\
130 \\
395 \\
78 \\
396\end{array}$ & $\begin{array}{l}2.9 \\
2.6 \\
1.8 \\
3.3 \\
1.8\end{array}$ \\
\hline \multicolumn{5}{|c|}{ Possible alternatives } \\
\hline $\begin{array}{l}{ }^{124} \mathrm{Sb}-\mathrm{Be} \\
88_{\mathrm{Rb}-\mathrm{Be}} \\
{ }^{101_{\mathrm{Mo}-\mathrm{Be}}} \\
{ }^{38} \mathrm{Cl}-\mathrm{Be} \\
{ }^{24} \mathrm{Na}-\mathrm{Be}\end{array}$ & $\begin{array}{l}60.0 \text { day } \\
17.8 \mathrm{~min} \\
14.6 \mathrm{~min} \\
37.29 \mathrm{~min} \\
14.96 \mathrm{hr}\end{array}$ & $\begin{array}{r}1692 \\
2088 \\
1836 \\
2080 \\
2170 \\
a_{2754}\end{array}$ & $\begin{array}{r}24 \\
376 \\
153 \\
369 \\
449 \\
973 \\
289\end{array}$ & $\begin{array}{l}5.6 \\
1.8 \\
2.4 \\
1.8 \\
1.7 \\
1.4 \\
2.6\end{array}$ \\
\hline
\end{tabular}

${ }^{a_{24}} \mathrm{Na-Be}$ produces two groups of neutrons for single gamma ray energy because gamma ray energy is greater than second excited state in beryllium.

TABLE II. - SOURCE PROPERTIES

\begin{tabular}{|c|c|c|c|c|}
\hline $\begin{array}{c}\text { Gamma ray } \\
\text { source } \\
\text { compound }\end{array}$ & $\begin{array}{c}\text { Solution } \\
\text { concentration, } \\
\mathrm{g} / 1000 \mathrm{~cm}^{3}\end{array}$ & $\begin{array}{c}\text { Percent } \\
\text { saturation }\end{array}$ & $\begin{array}{c}\text { Neutron } \\
\text { flux per curie, } \\
\text { neutrons } /\left(\mathrm{cm}^{2}\right)(\mathrm{sec})(\mathrm{Ci})\end{array}$ & $\begin{array}{c}\text { Neutron } \\
\text { flux, }\end{array}$ \\
\hline $\mathrm{Al}_{2}\left(\mathrm{SO}_{4}\right) \cdot 18 \mathrm{H}_{2} \mathrm{O}$ & 500 & $\sim 100$ & 55 & $3.3 \times 10^{3}$ \\
$\mathrm{MmSO}_{4} \cdot \mathrm{H}_{2} \mathrm{O}$ & 91.5 & $\sim 10$ & 28 & $1.4 \times 10^{4}$ \\
$\mathrm{Mn}_{2}\left(\mathrm{SO}_{4}\right)_{3}$ & 9.65 & $<1$ & 4 & $4.0 \times 10^{3}$ \\
\hline
\end{tabular}

Weutron flux is epicadmium neutron flux at center of sphere. 


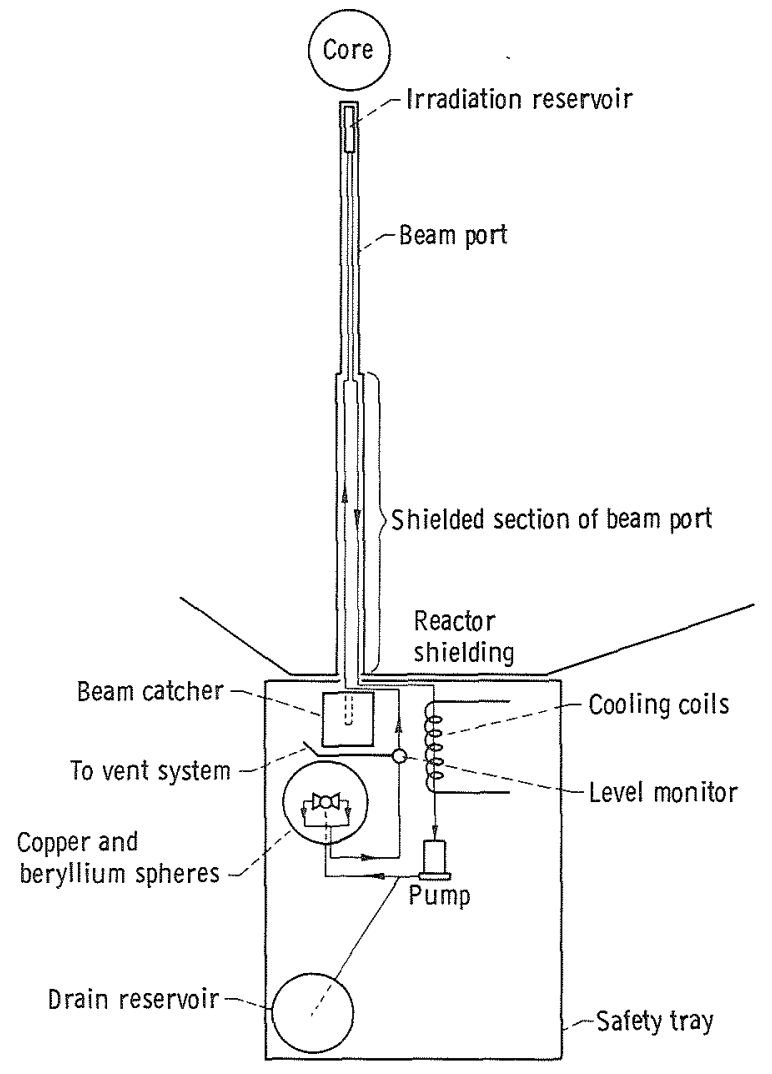

Figure 1. - Flow loop (top view).

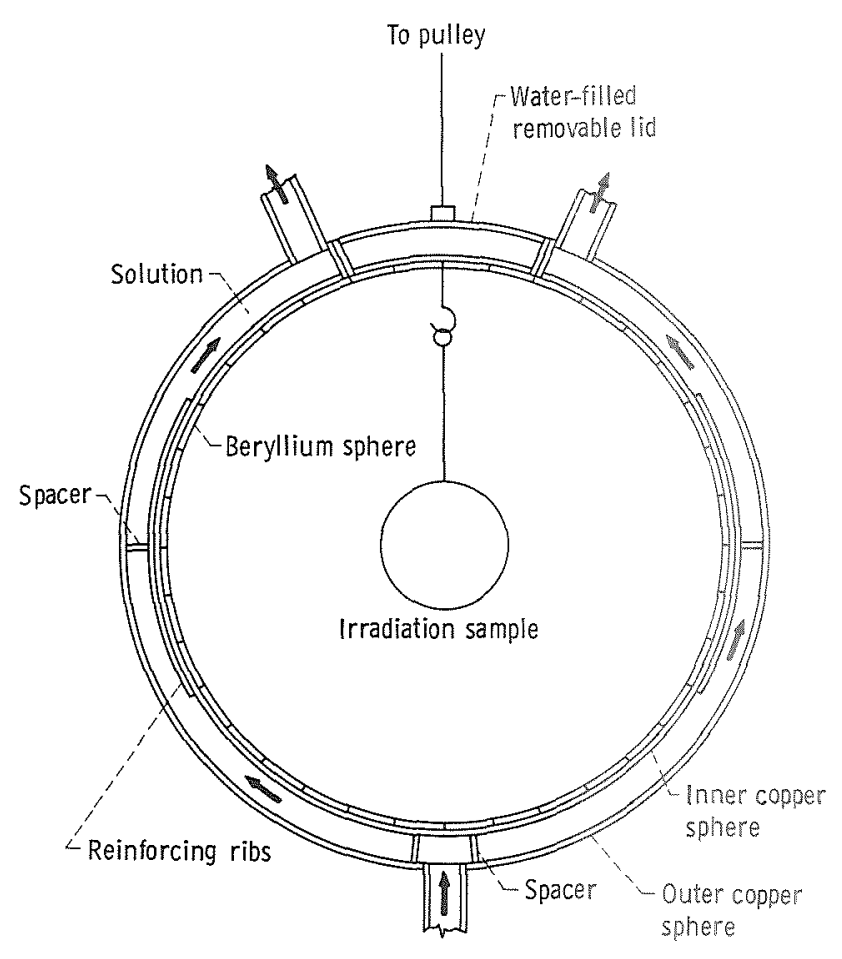

Figure 2. - Spherical isotropic neutron source (cross-sectional view). 


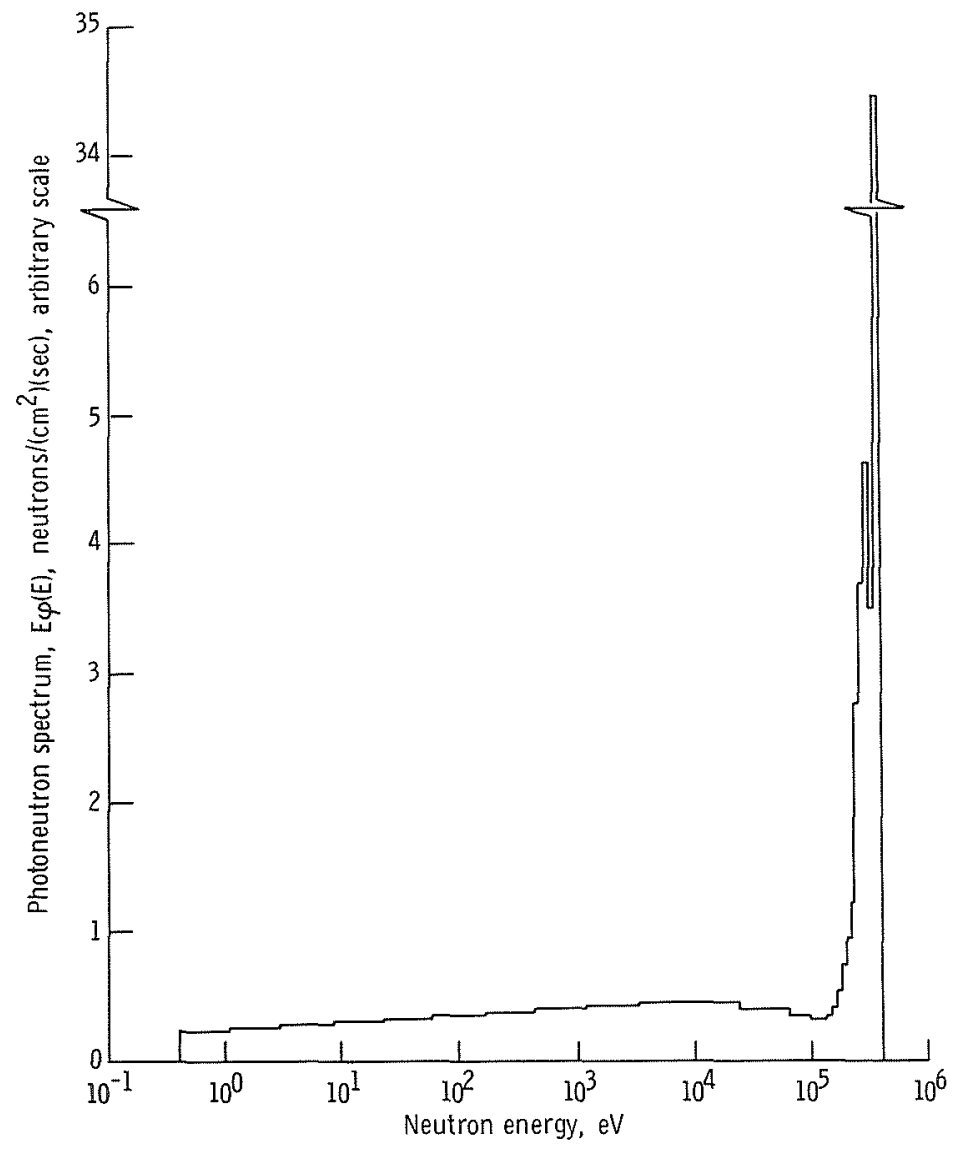

Figure 3. - Calculated photoneutron spectrum (source at $400 \mathrm{keV}$ ). 


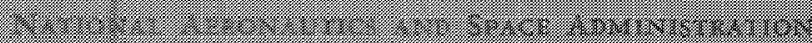

$$
\text { 古: }
$$
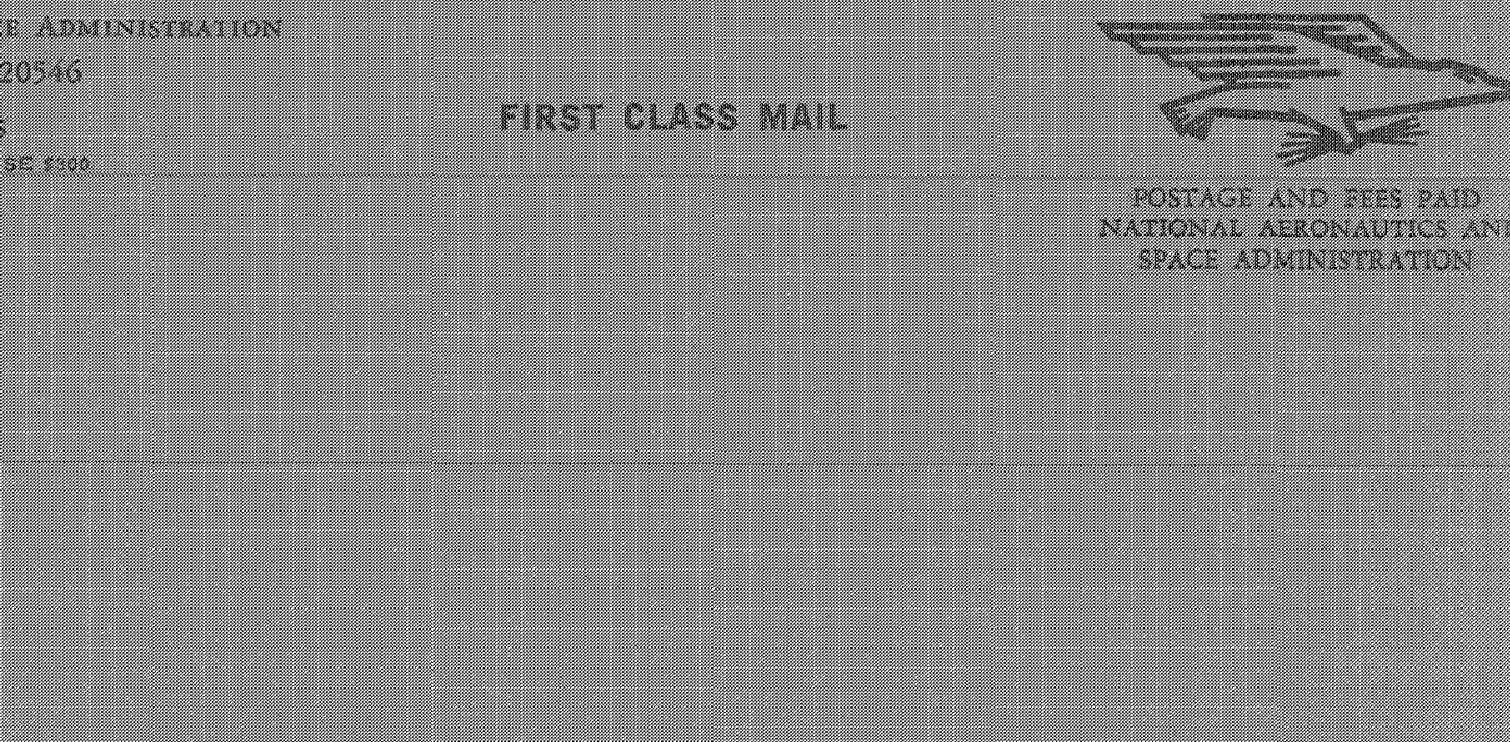

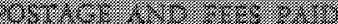

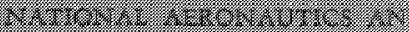

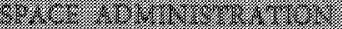

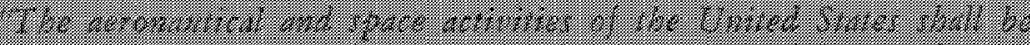

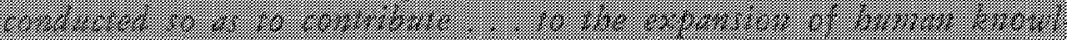

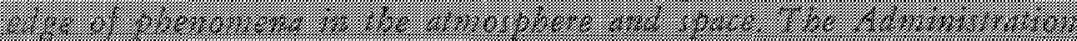

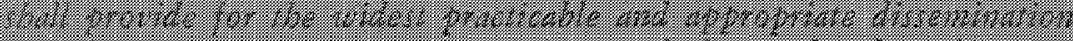

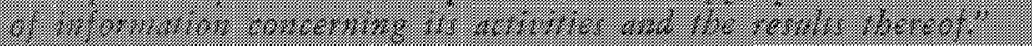

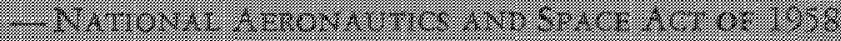

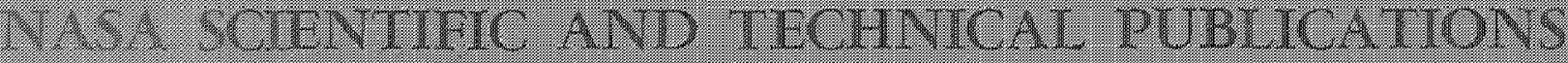

20.

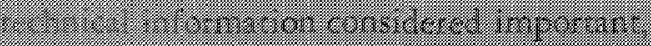

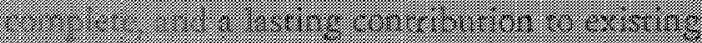

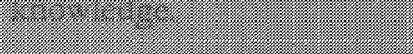

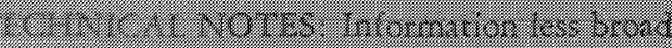

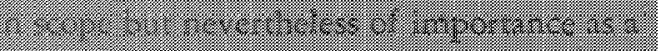

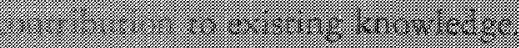

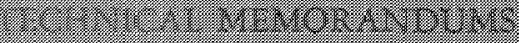

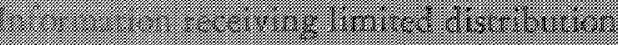

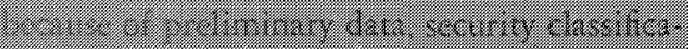

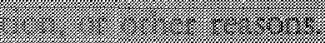

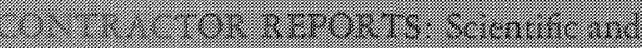

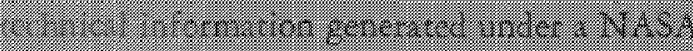

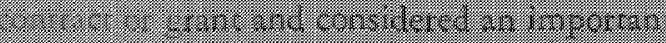

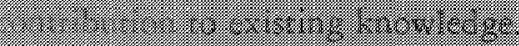

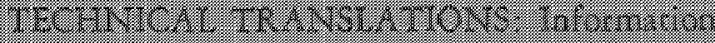

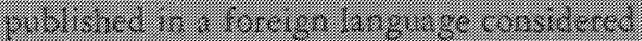

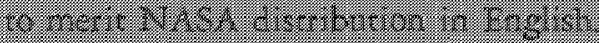

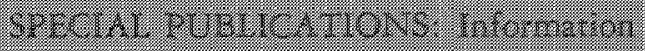

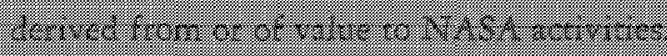

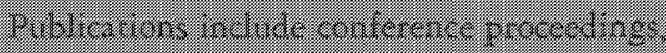

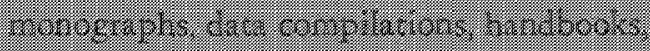

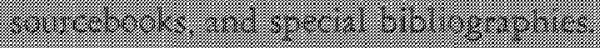

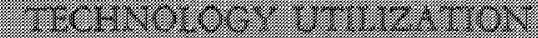

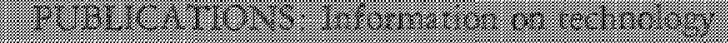

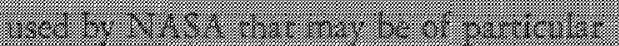

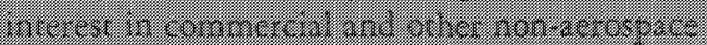

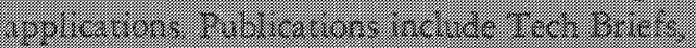

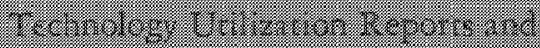

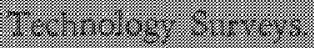

7.

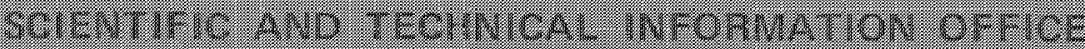
MAJOMAL AERONAUTICS AMD SPACE ADWINISTRATION

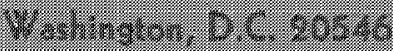

